\title{
Dynamic Behavior of Laminated Graphite/Epoxy Composite Under High-Strain Rate Perforation Loading
}

\author{
Sylvanus N. Wosu ${ }^{1} \&$ Qiaoyun Xie ${ }^{1}$ \\ ${ }^{1}$ Department of Mechanical Engineering, University of Pittsburgh, Pittsburgh, USA \\ Correspondence: Qiaoyun Xie, Department of Mechanical Engineering, University of Pittsburgh, Pittsburgh, PA \\ 15261, USA. E-mail: qix8@pitt.edu
}

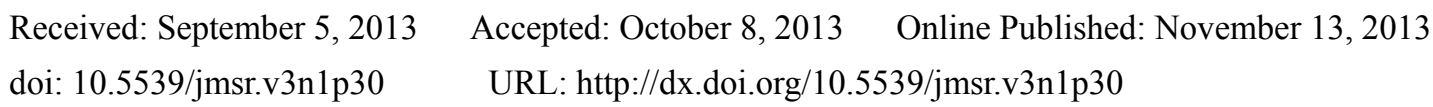

\begin{abstract}
A high strain rate perforation split Hopkinson pressure bar (P-SHPB) test apparatus was developed for the quantification analysis of energy expenditure in the penetration or perforation mechanics, and dynamic fracture failure processes of laminated graphite/epoxy composite. This paper described the basic features of the P-SHPB system for perforation testing, characterized of high strain rate, and single mode as well as mixed modes of fracture failures of laminated composites. The results showed that the energy expended in a perforation process depends on the thickness of the laminate samples, the impact parameters and the incident stress delivered to the composite. The failure modes in graphite/epoxy composite exhibited four regions of damage mechanism and characterized on the basis of energy absorbed, impact energy, loading force, sample stress and strain rate. Perforation limit velocity was estimated by extrapolating the (impact velocity) ${ }^{2}$ and crack length curve to a zero-damage length and determining the velocity value.
\end{abstract}

Keywords: P-SHPB, energy expenditure, high strain rate, failure modes, perforation limit velocity

\section{Introduction}

Composite materials are used in a variety of components for automotive, aerospace, marine and consumer products such as golf clubs, and tennis rackets due to their good mechanical properties as well as high strength to weight ratio. However, they are susceptible to high impact loads which may cause severe degradation of mechanical properties within a composite structure (Kang \& Lee, 1994; Shyr \& Pan, 2003). Understanding the modes of failure and energy absorption mechanism of laminated composite plates under dynamic loading conditions remains a challenge (Aktas, Balcioglu, Aktas, Turker, \& Deniz 2012; Hosur, Adbullah, \& Jeelani, 2005; Tan, Watanabe, \& Iwabori, 2012).

For laminated composites, the energy expended due to permanent composite plate damage is distributed among four different modes of fracture, namely, transverse matrix cracks, fiber fracture, fiber-matrix interface response and delamination. Delamination is identified as the dominant fracture mode in laminated graphite system (Waas, Takeda, Yuan, \& Lee, 1997; Woldenbet \& Vinson, 1997). Research by Weeks (Weeks \& Sun, 1998) suggested that vertical matrixes cracks near laminate's top and bottom surfaces are due to bending stresses while slanted matrix cracks in the laminate are the result of transverse shear stress. Delamination was attributed to pure bending and shear induced crack propagation. Through-the-thickness shear stress plays a dominant role in crack initiation and delamination whereas through-the-thickness normal stresses have little effect (Vaidya, Jadhav, Hosur, Gillespie Jr., \& Fink, 1999). It is generally believed, and corroborated by experiments, that the propagation of damage is mainly initiated by the tensile wave through the thickness (Chen \& Chandra, 2004; Espinosa, Dwivedi, \& Lu, 2000).

Studies (Dee, Vinson, \& Sankar, 1997) have shown that energy expended in the damage process is proportional to the thickness of the target plate and the energy absorbed and damage sustained are not linear functions of impact (energy) velocity. Within a certain range, the damage mechanism appears dependent on energy absorbed by the sample, while within other energy ranges, the damage mechanism appears governed by the striker velocity. Thus, the use of the damage threshold impact energy alone to characterize the damage event may not be an ideal criterion and maybe influenced by other mechanisms. Of interest is to understand the wave-induced damage near the perforation limit threshold and to characterize the modes of fracture which occur. 
The purpose of this paper is to achieve a state of penetration analogous to that produced by a projectile at the perforation limit velocity. To accomplish this, the split Hopkinson bar system is modified at the point of specimen contact. A conical hemispherical nosed penetrator is attached to the incident bar, while a fixture holding the specimen is attached to the transmitted bar. Compared to conventional perforation projectile experiments, the Hopkinson bar is ideally suited for examining the effects of projectile (penetrator) velocity and the resulting stress wave, on damage generated within laminated plates. Hopkinson bar penetration experiments allow precise positioning of the impact site, control of the damage process through the delivered wave form, and the ability to quantify the damage process through stress wave analysis.

\section{Experimental Procedure}

\subsection{Installation and Calibration of the Hopkinson Impact System}

Figure 1 is a schematic diagram of the perforation assembly for the Hopkinson bar system. The figure shows the penetrator and specimen support that holds the composite plate. The fixture is sandwiched between the incident and transmitter bars as shown. The penetrator is attached to the end of the incident bar through its inner diameter. The sample holder fixture is attached to the transmitter bar with its open end facing the indenter. The space between the end of the fixture and the backside of the test plate allows for complete penetration or perforation beyond the thickness of the plate without reaching the end of the fixture. (In experiments performed near and beyond the perforation threshold, the penetrator could punch through and impact the end of the steel fixture and could result in damage to the indenter.) The collar prevents the indenting end from reaching the end of fixture. In the current investigation, composite layers were fabricated using plain carbon fabric 4060-6 style with $10 \mathrm{oz} / \mathrm{sq}$ yard and SC-15 epoxy resin system. The laminates were fabricated by VARIM process in the Center for Advanced Materials of Tuskegee University.

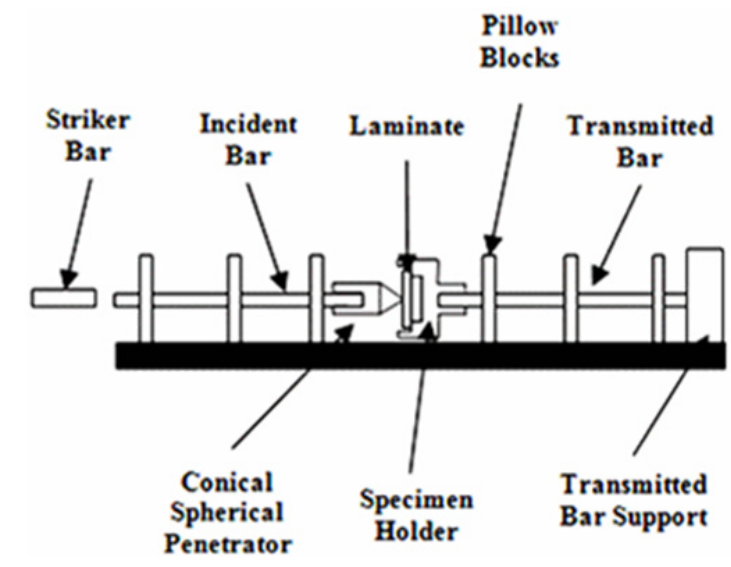

Figure 1. Schematic Diagram of the P-SHPB System Showing Perforation Sample Holder Fixture

The conical hemispherical-nosed penetrator was made out of maraging steel. Shown in Figure 2, the outer diameter is $38.10 \mathrm{~mm}$ and inner diameter hole is $25.4 \mathrm{~mm}$ drilled and recessed to allow the penetrator to sit properly on the incident bar when coupled to reduce mismatch effect between the incident bar and the penetrator. The conical end is $12.7 \mathrm{~mm}$ long with the protruding end extending 0.14 -inch long. The protruding section allows the specimen deformation to be achieved by not allowing the conical section to take part in the specimen failure response. The total length of the penetrator is $72.64 \mathrm{~mm}$ long.

The experimental parameters for the sample and system are described in Table 1. 


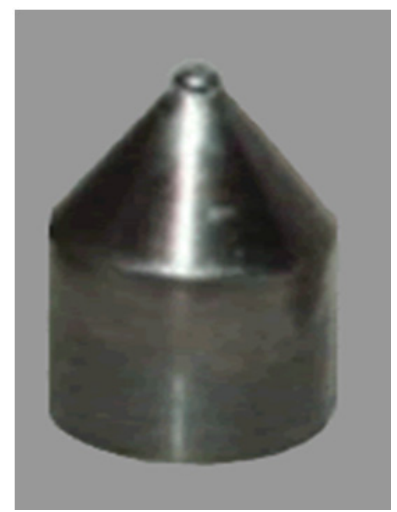

Figure 2. Conical hemispherical-nosed penetrator

Table 1. Experimental Parameters

Specimen Parameters:

Samples Diameter: 2.43 inches $(61.7 \mathrm{~mm})$

Composite sample type:

a) 16-, 32-Ply plain carbon fiber composite 4060-6 style and SC-15 resin system with a thickness of 0.27 $\mathrm{mm} / \mathrm{ply}$

b) Lay-up $[ \pm 45 / 0 / 90]_{\mathrm{ns}}$

System Parameters:

Hopkinson Pressure Bar:

Young's modulus of maraging steel bar:

Wave velocity in maraging steel bar:

Bar length:

Density of maraging steel:

Impact Parameters:

Penetrator:

Striker bar length:

Ram displacement:

Compressed air pressure:
$2.07 \times 10^{11} \mathrm{~Pa}$

$5010 \mathrm{~m} / \mathrm{s}$

$3.66 \mathrm{~m}$

$8000 \mathrm{~kg} / \mathrm{m}^{3}$

A calibration curve is established as a correlation between the impact pressure and striker impact velocity delivered to the input bar. The striker velocity just before impacting the incident bar was measured as a function of impact pressure using two infrared photo gate detectors. A pair of infrared detectors mounted on the striker bar measures the average velocity of the striker bar just before impact with the incident bar. A second set of infrared detectors on the incident bar measures the forward velocity of the incident bar. The kinetic energy of the striker bar (referred to impact energy in this paper) is then calculated from the known mass of the striker bar. The striker impact energy is proportional to the penetration/perforation energy and is directly controlled by the experimenter by simply controlling the compressor air pressure.

Figure 3 depicts the calibration curves showing nonlinear relationship between the striker impact velocity, energy and pressure. The data have been represented by a nonlinear curve fitting schemes that gave the following empirical equations:

$$
\begin{aligned}
& V_{I}=-2.08+11.5 p^{0.53} \\
& E_{I}=\frac{1}{2} m_{s} V_{I}^{2}=-2.19+60.4 p^{1.29}
\end{aligned}
$$

where $m_{s}$ is the mass of the $0.61 \mathrm{~m}$ striker bar equal to $2.47 \mathrm{~kg}$, the compressor pressure $p$ is in MPa, striker 
impact velocity $V_{I}$ is in $\mathrm{m} / \mathrm{s}$, and striker impact energy $E_{I}$ is in Joules.

\subsection{Data Analysis}

The basic assumptions and validity of Split Hopkinson Pressure Bar (SHPB) in the study of the dynamic behavior of materials are well documented (Bickle, 1970; Sierakowski, 1997; Zukas, Nicholas, Swift, Greszczuk, \& Curran, 1992). These assumptions are true for the present investigation, namely, minor local heat generated during the penetration does not change the material properties of the specimen; the Hopkinson bar is elastic and wave propagation within the bar follows elementary wave theory; the slender cross sectional bar of ratio is $d / L<1 / 50$, where $d$ and $L$ are diameter and length of the bar, respectively; Shape of the wave is non-dispersive and it remains unchanged during propagation along the bar. That is, plane wave will remain planar and parallel to the cross section during propagation from one section to another; the state of the stress is in equilibrium along the entire bar at any instant of strain measurement due to the dynamic impact by having a long bar and a thin specimen; transverse strain, lateral inertia, body forces, parasite waves are all negligible. For the P-SHPB, it is assumed that the effect of fixture and penetrator's head on the stress waves' configuration in the bars is small enough to be neglected for specimens in the setup used for P-SHPB experiments. It is further assumed that sample strain is much greater than the total strain of the bar and the specimen fixture. These assumptions were carefully investigated for the present setup and found to be satisfied.

Assuming a uniform stress through a thin specimen, $\varepsilon_{t}(t)=\varepsilon_{i}(t)+\varepsilon_{r}(t)$, the sample stress, strain, and strain rate can be expressed as:

$$
\begin{aligned}
& \sigma_{s}(t)=\frac{A_{b}}{A_{s}} E_{0} \varepsilon_{t}(t) \\
& \varepsilon_{s}(t) \approx \frac{-2 c_{0}}{L_{e}} \int_{0}^{t} \varepsilon_{r}(t) d t \\
& \dot{\varepsilon}_{s}(t) \approx \frac{-2 c_{0}}{L_{e}} \varepsilon_{r}(t),
\end{aligned}
$$

where $\varepsilon_{i}, \varepsilon_{r}$, and $\varepsilon_{t}$ are the incident, reflected, and transmitted strain pulses, $L_{e}$ is the effective sample length, $E_{0}$ is Young's modulus, $c_{0}$ is wave velocity of bars, $A_{b}$ and $A_{s}$ are areas of bars and sample, respectively.

In a typical perforation test, the penetrator emerges through the plate of thickness $\left(L_{s}\right)$ to the maximum distance, $\delta=L_{s}+h$, where $h$ the distance the penetrator travels beyond the plate thickness during punch-through the rear surface of the laminate or estimated as the fiber damage height as depicted in Figure 4.

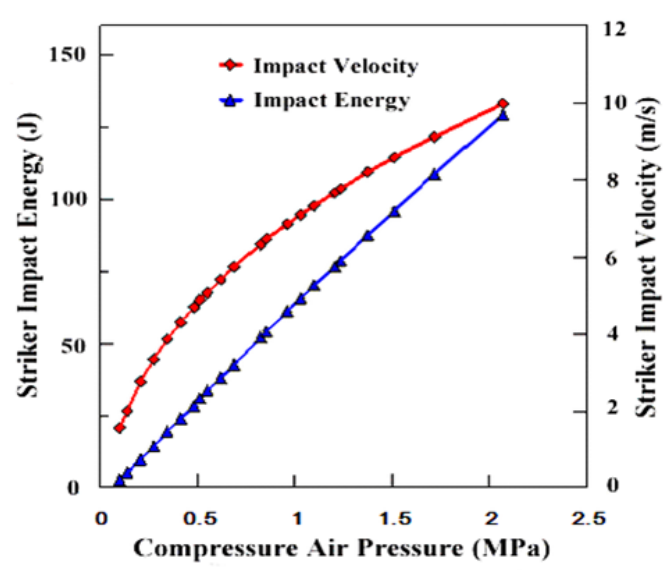

Figure 3. Striker impact energy and velocity as a function of compressor pressure

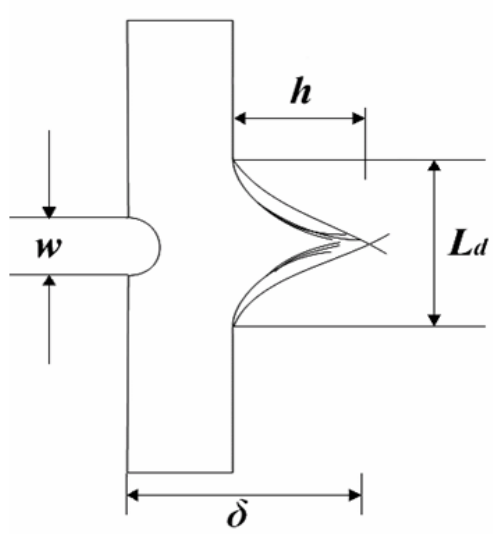

Figure 4. Schematic of perforated laminate showing definitions of $h, w, L_{d}$ used in data analysis

Consider $d E_{\alpha}=P(\alpha) d \alpha$ as the energy expended by the penetrator as it penetrates the specimen depth $d \alpha$ including the additional energy required for punch through. The kinetic energy of the penetrator is equal to work done by the penetrator compressive load such that the work-energy relation can be written as: 


$$
E_{I}=\frac{1}{2} m_{s} V_{I}^{2}=\int_{0}^{\delta} P(\alpha) d \alpha=\int_{0}^{L_{s}} P_{1}(\alpha) d \alpha+\int_{L_{s}}^{\delta} P_{2}(\alpha) d \alpha+E_{L}
$$

where $\delta-L_{s}=h$ is the maximum penetration or perforation depth above the composite plate, $P(\alpha)$ is the penetrator contact force for perforation. The total energy delivered and expended in the process can be decomposed into energy required to just perforate the plate $\left(E_{p e r}\right)$, energy losses in the process $\left(E_{L}\right)$, work done in displacing the penetrator by an amount $h$ beyond the plate (equal to the residual energy retained by the penetrator and the bars $E_{r}$ ) and can be expressed as:

$$
E_{I}=\frac{1}{2} m_{s} V_{I}^{2}=\int_{0}^{\delta} P(\alpha) d \alpha=E_{p e r}+E_{r}+E_{L}
$$

The residual energy after perforation can be modeled as the work done by an average contact force over the duration of the perforation in moving a distance $h$ above the plate thickness and given as (Nwosu, 1997):

$$
\begin{gathered}
E_{r}=\bar{F}_{c} h=\frac{1}{2} m_{b} V_{r}^{2}=E_{I}-E_{P e r}-E_{L} \\
E_{p e r}=\frac{1}{2} m_{b} V_{p e r}{ }^{2}
\end{gathered}
$$

where $F_{c}$ is the average contact force over the duration of the perforation event and is determined from the integration of the force-time. $V_{p e r}$ is the perforation velocity, and $m_{b}$ is the mass of the $3.66 \mathrm{~m}$ input bar equal to $14.6 \mathrm{~kg}$. To determine the critical (perforation limit) velocity for specimen perforation, one can use deterministic or probabilistic techniques (Zukas et al., 1992). In this research, perforation or complete penetration of laminated target occurs when the penetrator-head just traverses and exits the rear surface of the target. If perforation depth $(h)$, the initial striker bar input energy $E_{I}$, and $F_{c}$ are known as in this case, perforation velocity is expressed as:

$$
V_{P e r}=\sqrt{\left(\frac{2}{m_{b}}\left(E_{I}-\overline{F_{c}} h\right)\right)}
$$

Substituting Equation (5) into Equation (6) and neglecting all energy losses, the residual velocity can be written as:

$$
V_{r}^{2}=V_{I}^{2}-V_{p e r}^{2}=\left(\frac{2}{m_{b}} \overline{F_{c}} h\right)
$$

The impact velocity can be written in terms of damage height, residual velocities and average contact force as:

$$
\begin{aligned}
& V_{I}^{2}=V_{p e r}{ }^{2}+V_{r}^{2} \\
& V_{I}^{2}=V_{p e r}{ }^{2}+\left(\frac{2}{m_{b}} \overline{F_{c}}\right) h
\end{aligned}
$$

Thus, a plot of striker impact velocity versus residual velocity or penetrator depth above the plate can be used to estimate the threshold velocity required for incipient perforation. The perforation limit velocity $\left(V_{P \mathrm{~L}}\right)$ is the striker velocity just to perforate the plate with residual velocity or penetrator depth equal to zero. That is, $V_{I}=$ $V_{p e r} \approx V_{P \mathrm{~L}}$ at $h=0$ or $V_{r}=0$. This satisfies that all the energy at the point of perforation is used up for the perforation damage with zero residual energy. The perforation limit velocity in high bar mass-low velocity perforation/penetration type experiments in P-SHPB is similar in principle to the ballistic limit velocity in low mass-high velocity perforation experiments in ballistic projectile experiments.

\section{Results and Discussions}

\subsection{Dynamic Responses of Compressive Stress Wave}

Figure 5 shows typical incident, reflected, and transmitted stress pulses determined from the measured strain signal using appropriate system calibration. The incident wave reaches the strain gage located at $1.829 \mathrm{~mm}$ in $395 \mu \mathrm{s}$ and $790 \mu \mathrm{s}$ to the bar/specimen interface at $3.658 \mathrm{~m}$. This represents a wave speed of $4630 \mathrm{~m} / \mathrm{s}$ compared to the $5010 \mathrm{~m} / \mathrm{s}$ theoretical value (Rossing \& Russell, 1990), a difference of less than 10 percent. It is noted that the theoretical wave speed is determined from the density and elastic modulus data supplied for the maraging steel Hopkinson bar material. Part of this incident wave is reflected back and travels the same time (395 $\mu \mathrm{s})$ to reach the strain gage on the incident bar. Without a specimen, the transmitted wave will also begin its traverse time at the same time as the reflected wave and will reach the strain gage on the transmitter bar after $395 \mu$ s. The waveform is captured at a sample rate of 250,000 samples/sec at $35 \mathrm{~J}$ and $89 \mathrm{~J}$. The $35 \mathrm{~J}$ for no penetration shows more than two full reflections before the wave experiences any distortion compared to the $89 \mathrm{~J}$ wave that is completely smooth after two full waves. This is because this energy is post-perforation with most of the residual 
energy returned to the system. In the case of partial penetration (with the penetrator head inside the specimen), Nwosu (1997) has shown that the distortion of the wave will be more significant due to the global effect of the penetrator inside the specimen. Strain wave pulse from P-SHPB experiment provides information for complete characterization of the damage process.

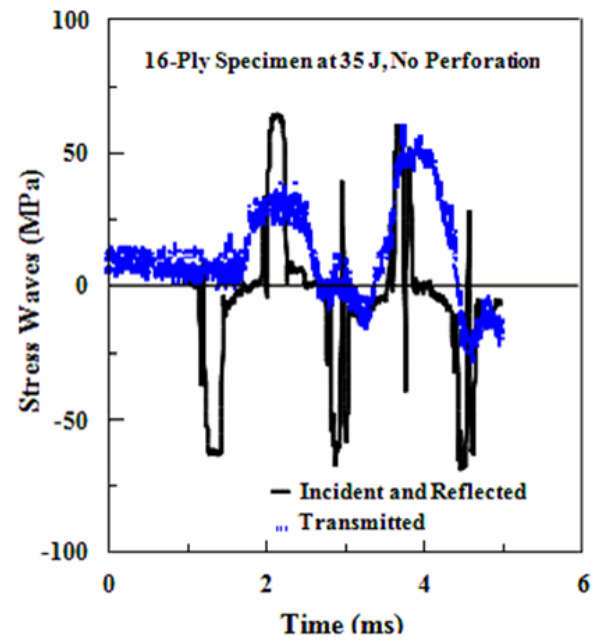

(a)

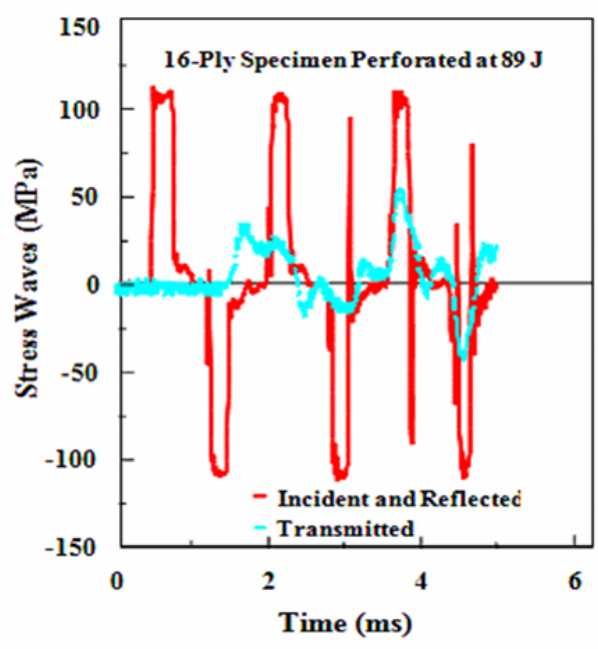

(b)

Figure 5. Comparison of incident, reflected and transmitted stress waves for (a) $35 \mathrm{~J}$ with no incipient damage and (b) $89 \mathrm{~J}$ with perforation 16-ply laminate

Figures 6-8 illustrate dynamic responses of laminated composite in terms of strain rate, force, energy absorption, and strain behaviors for composite penetrated with a conical hemispherical-nosed penetrator. The results show that failure response behaviors are strongly dependent on impact energy or compressive incident stress level. The typical complete penetration (perforation) process of laminated composite generally involves five stress-induced inter-dependent damage events: compression induced matrix cracking and fiber fracture, shear plug formation, plug separation, delamination, and perforation.

Figure 6 shows the time history of strain rate for various impact energies. For all of the striker impact energies, the specimen rapidly reached a constant strain rate within the first 100 microseconds of the test and remained constant for more than 250 microseconds. The rate at which the composite plate deforms under dynamic loading condition of the incident compressive stress wave is an important damage characterizing parameter since it determines the validity of the experimental data. A critical assumption of using a Hopkinson bar test is for the stress wave to be uniform within the specimen. Generally, thinner specimen corresponds to a higher strainer rate.

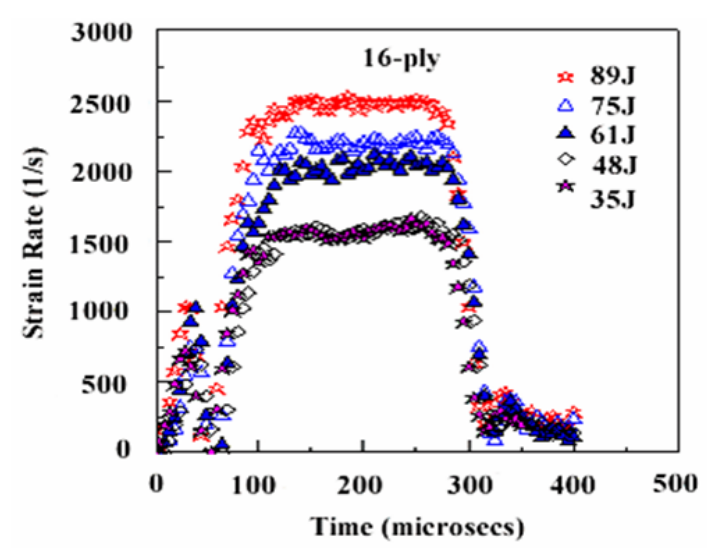

(a)

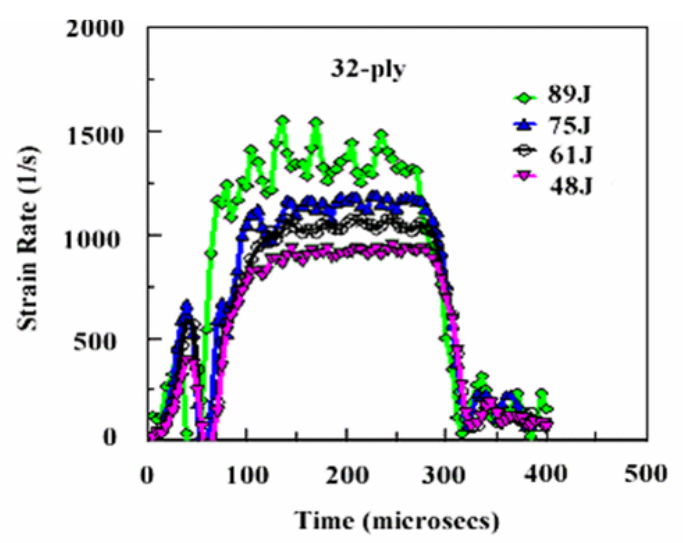

(b)

Figure 6. Time histories of strain rate with varying impact energies for (a) 16-ply and (b) 32-ply graphite/epoxy laminates 
Figure 7 depicts the displacement history of loading force. The first stage in laminate failure response is mainly compressive and corresponds to initial loading and unloading stage of the plate by the incident compressive stress. The penetrator velocity being greater than that of the laminate's flexure characterizes the compressive loading stage. Since the perforating velocity is greater than the laminate's forward velocity, it is conceivable that initial matrix cracking and penetration are dependent on the threshold kinetic energy at which these events occur. The specimen experiences the highest compressive stress within the first few microseconds of interaction with the compressive incident wave and continues to deform even after this stress is unloaded. The loading force increases as the plate is pushed or flexed forward with increasing particle velocity which is the velocity measured at the end of incident bar, and decreases as the plate is unloaded. The tensile release wave in the force-displacement curve in Figure 7 is caused by impedance mismatch at the specimen/transmitter bar interface at the rear surface of the specimen. The results indicate higher amplitude of the tensile release wave for the 32-ply specimen. A higher release wave in the thick sample is mainly due to higher strain energy.

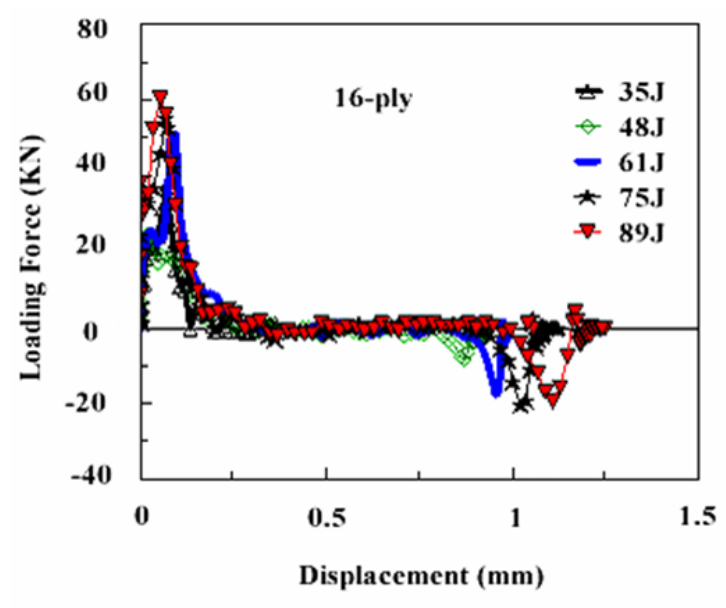

(a)

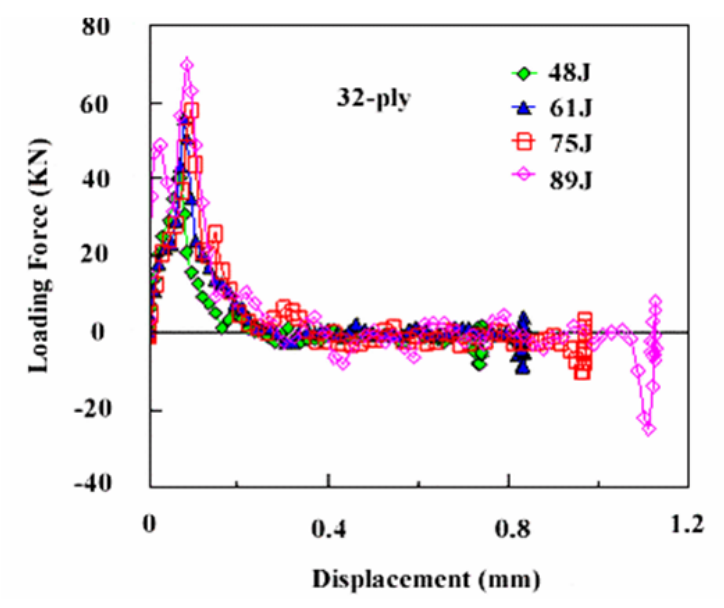

(b)

Figure 7. Force-displacement curves for (a) 16-ply and (b) 32-ply graphite/epoxy at varying impact energies

The variations of residual energy absorbed with striker impact energy, strain rate, displacement and particle velocity, are shown in Figure 8 for 16- and 32-ply graphite epoxy. Figure 8a shows that residual energy absorbed is slightly higher for the 32-ply laminate at same striker impact energy and the effect is a little more significant at higher impact energy above the damage threshold. Energy absorbed and strain rate curve in Figure $8 \mathrm{~b}$ shows that the residual energy absorbed is highly sensitive to strain rate and more significant for 32-ply laminate than 16-ply one. This may be attributed to the fact that a thick plate dissipates a greater portion of the incident energy because of greater penetration damage resistance encountered. For the same impact energy, the thicker plate supports compressive wave of higher amplitude than the thin plate with the wave expending more time in traversing a thick plate. More energy is required for damage a thick plate than a thin one. The reverse effect is evident for particle velocity and displacement in Figures $8 \mathrm{c}$ and $\mathrm{d}$. The residual energy absorbed increases with particle velocity and displacement but higher for 16-ply specimen than the 32-ply sample due to higher elastic strain energy released in thick laminate. The energy retained by the composite plate is only slightly different at low energies. High energy absorbed by the specimen indicates low strain energy released after failure and therefore higher material compressive strength. Thus, it provides a good estimate of strain energy to failure or the residual properties of the damage process. 


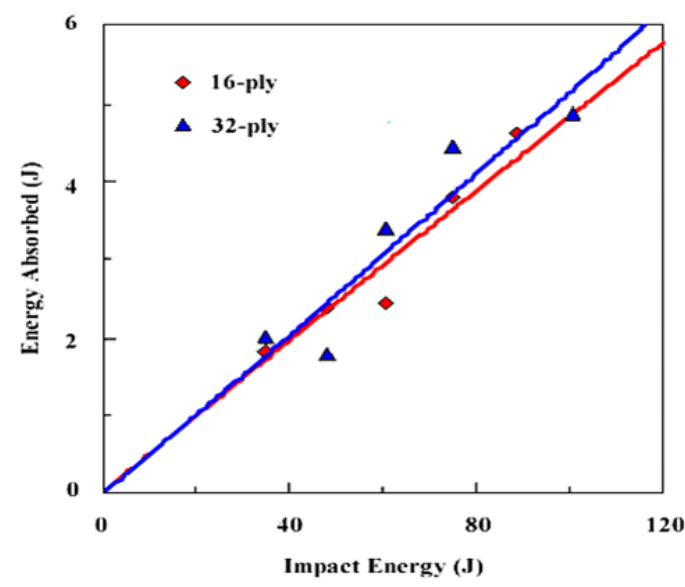

(a)

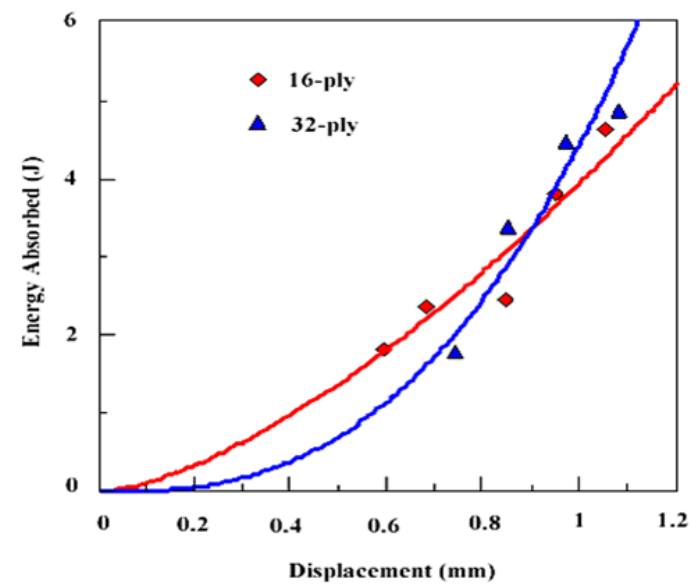

(c)

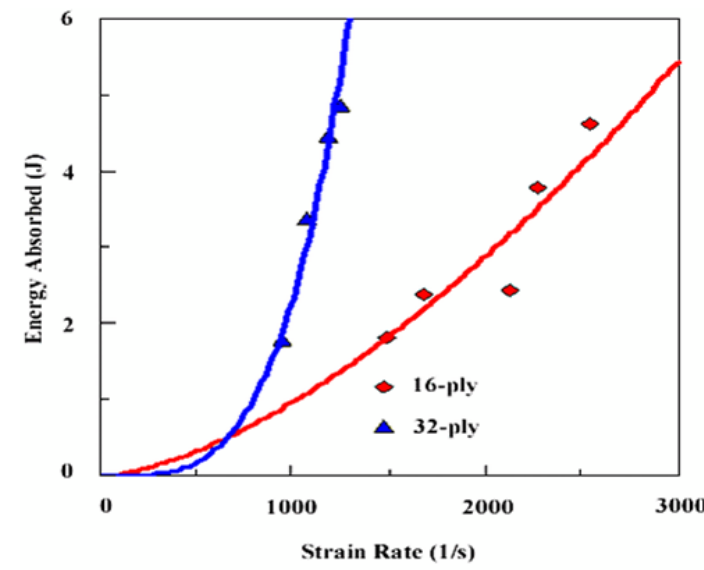

(b)

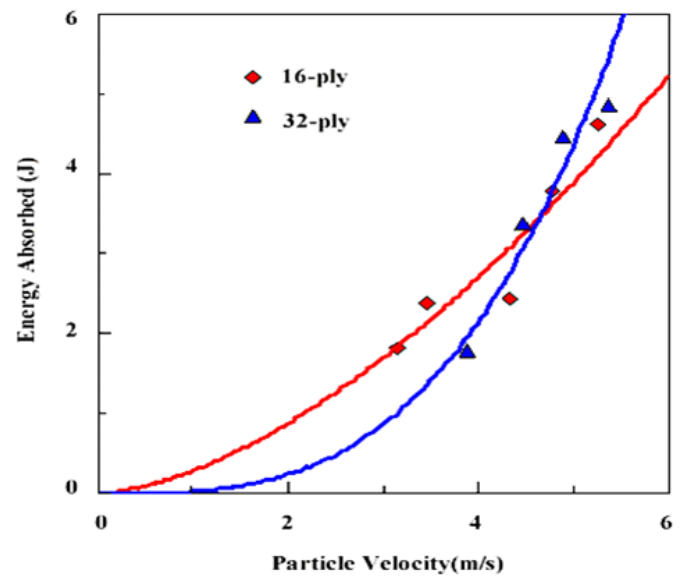

(d)

Figure 8. Dependency of energy absorbed by laminate on (a) impact energy, (b) strain rate, (c) displacement and (d) particle velocity for 16- and 32-ply graphite/epoxy composite plates

\subsection{Damage Propagation and Classification of Modes of Failure}

The variations of energy absorption with sample stress for 16-ply composite laminates are shown in Figure 9. It appears that there are four damage zones as marked in the figure. Energy absorbed increases rapidly at $0-0.5$ MPa sample stress (Mode I), increases slowly for 0.5-2 MPa sample stress (Mode II), reaches and remains at a constant value for 2.0-4.0 MPa (Mode III), and starts to decrease for sample stress above $4 \mathrm{MPa}$ (Mode IV) beyond $300 \mu \mathrm{s}$. The change of energy absorbed with change in sample stress clearly indicates the point of change in slope and deviation from initial linear behavior. The point of deviation is an indication of transition from initiation of crack to crack growth and other damage mechanisms such as fiber breakage, delamination and perforation. After perforation is achieved, a nonlinear relationship exists between sample stress and energy absorbed. 


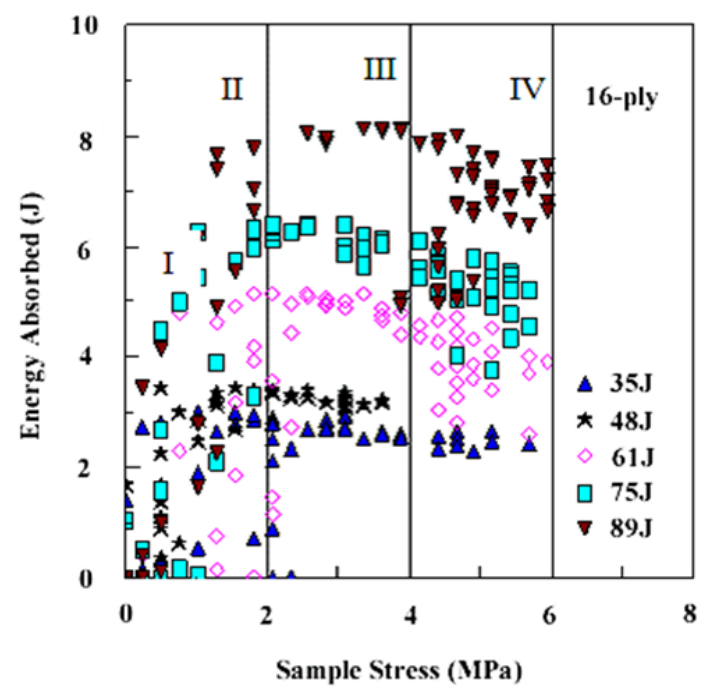

Figure 9. Variations of energy absorption with sample stress for 16-ply graphite/epoxy specimen at varying impact energies

Figure 10 reveals the variation of a damage event as impact energy for 1/4-inch conical hemispherical-nosed penetrator. Rear surface cracks on the specimen were first observed at impact energy $35 \mathrm{~J}$. Cracks propagate as impact energy increases, and perforation is achieved at $75 \mathrm{~J}$. The specimen is completely punched through at $89 \mathrm{~J}$. Thus based on the visual examination of the surface damage generated in the 16-ply specimen from 35-89 J impact energy range, Mode I is characterized by elastic failure such as micro-buckling of the fibers or initiation of matrix micro cracks. Mode II is characterized by the onset of crack propagation and delamination leading to plastic deformation in Mode III as the bulk modulus of the specimen increases. The system and plate returns to equilibrium in Mode IV by losing some of the absorbed strain energy. The 16-ply curve shows a greater scatter in Mode III due to oscillations caused by greater damage event and generation of permanent deformation such as fiber breakage, delamination or perforation depending on the compressive strength of the composite material.

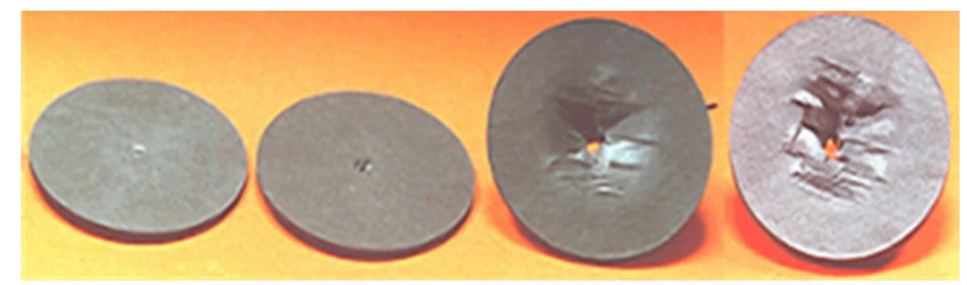

Figure 10. Damage propagation of 16-ply graphite/epoxy specimen using 1/4-inch conical hemispherical-nosed penetrator for impact energy at $35 \mathrm{~J}, 61 \mathrm{~J}, 75 \mathrm{~J}$ and $89 \mathrm{~J}$ respectively

Further characterization of the damage process in regions of failure is investigated. Table 2 gives sample stress, impact energy and strain rate ranges corresponding to four failure modes. The classification is based only on the 16-ply specimen that was tested on and above its damage threshold. Figure 11 is a convenient representation of the characterization of the four failure modes. For example, the figure shows that a mode III perforation damage is on the averaged reached at $4.0 \mathrm{~J} / \mathrm{ply}$ at a strain rate of $2100 \mathrm{~s}^{-1}$ for sample stress $35 \mathrm{kPa} / \mathrm{ply}$. Compared to actual experiment, error in the above classification and prediction of a specific failure mode ranges from $0.5 \%$ to $15 \%$. 
Table 2. Classification of failure mode of 16-ply graphite/epoxy composite plate

\begin{tabular}{ccc}
\hline $\begin{array}{c}\text { Failure } \\
\text { Regions }\end{array}$ & $\begin{array}{c}\text { Sample Stress (KPa/ply), Impact Energy } \\
(\mathrm{J} / \mathrm{ply}) \text { and strain rate }(1 / \mathrm{s})\end{array}$ & Characteristics Failure Mode \\
\hline I & $5<\sigma_{\mathrm{I}} / \mathrm{ply}<10, \mathrm{kPa} / \mathrm{ply}$ & Elastic response; possible fiber \\
& $1.5 \leq \mathrm{E}_{\mathrm{I}}<2.5, \mathrm{~J} / \mathrm{ply}$ & \\
& $1000<\mathrm{SR}<1250,1 / \mathrm{s}$ & \\
& $10<\sigma_{\mathrm{II}} / \mathrm{ply}<25, \mathrm{kPa} / \mathrm{ply}$ & Matrix cracking and crack propagation; \\
II & $2.5 \leq \mathrm{E}_{\mathrm{I}}<3.5, \mathrm{~J} / \mathrm{ply}$ & fiber breakage; delamination \\
& $1250<\mathrm{SR}<2000, \mathrm{kPa} / \mathrm{ply}$ & \\
& $25<\sigma_{\mathrm{III}} / \mathrm{ply}<50, \mathrm{kPa} / \mathrm{ply}$ & Extended delamination; perforation \\
III & $3.5 \leq \mathrm{E}_{\mathrm{I}}<4.5, \mathrm{~J} / \mathrm{ply}$ & \\
& $2000<\mathrm{SR}<2500,1 / \mathrm{s}$ & \\
& $\sigma_{\mathrm{IV}} / \mathrm{ply}>50, \mathrm{kPa} / \mathrm{ply}$ & Punch-through and plugging; \\
$\mathrm{IV}$ & $\mathrm{E}$ I $\geq 4.5, \mathrm{~J} / \mathrm{ply}$ & fragmentation \\
& $\mathrm{SR}>2500,1 / \mathrm{s}$ &
\end{tabular}

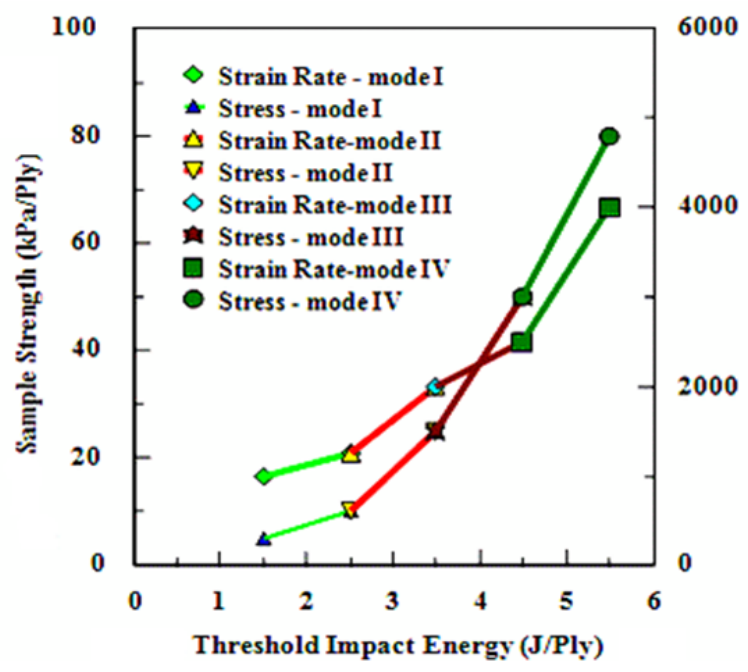

Figure 11. Classification of failure modes of 16-ply graphite/epoxy composite plate

\subsection{Estimation of Perforation Limit Velocity}

As further characterization of the damage process, the height $(h)$, surface crack length at the rear surface $\left(L_{d}\right)$, and entrance width $(w)$ of 16-ply specimen are shown in Figure 4. The length of the surface crack growth was observed to begin to grow when the impact energy is above a certain threshold value. Earlier investigators (Vinson \& Woldersenbet, 2001) assumed a linear fit to surface damage area obtained from C-scan and demonstrated a threshold impact velocity above which cracks will begin to propagate. Surface data in the present studies did not follow a linear behavior. Figure 12 (a-b) show the variation of crack extension and (residual velocity $)^{2}$ with (impact velocity) $)^{2}$. The threshold velocity was obtained by extrapolating the line to a zero-damage length and determining the velocity value at which $L_{d}$ to zero. Thus, the threshold impact velocity for surface crack can be obtained as $V_{t h}=7.35 \mathrm{~m} / \mathrm{s}$. Rear surface crack in the 16-ply specimen was first observed when the impact energy was $35 \mathrm{~J}$. This corresponds to a critical impact velocity of $7.35 \mathrm{~m} / \mathrm{s}$ using the analytical Equation (8). 


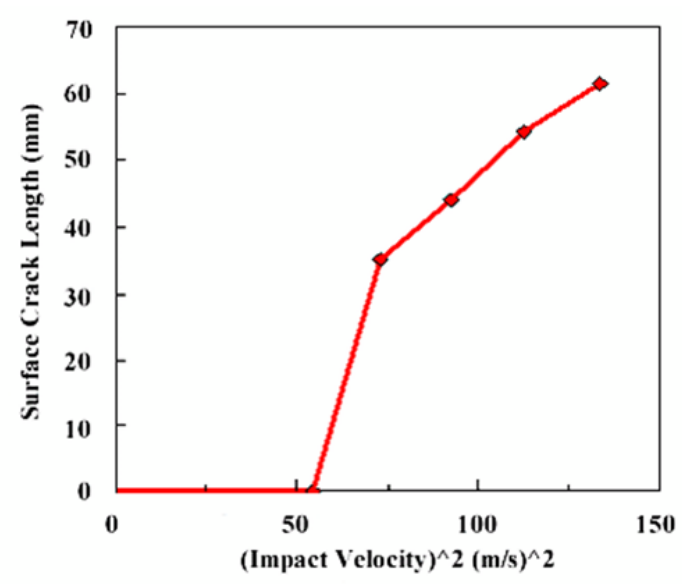

(a)

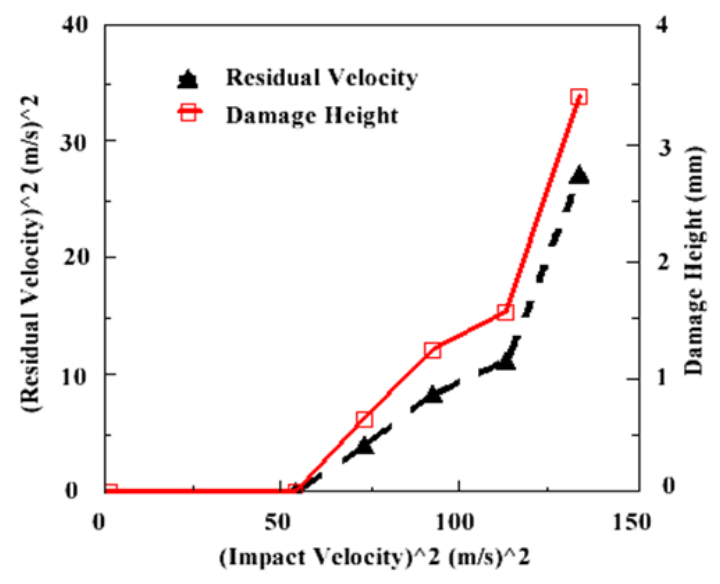

(b)

Figure 12. (a) Surface crack length and (b) (residual velocity) ${ }^{2}$ and damage height variations with (impact velocity) ${ }^{2}$ for 16-ply graphite/epoxy

The analysis above could be extended to determine perforation limit velocity (generally defined as the threshold impact velocity above which the penetrator will just perforate the specimen without any residual velocity or energy). Since a surface crack is usually initiated before a perforation by an penetrator is achieved, the perforation limit velocity will be equal to or higher than the surface crack initiation velocity $(7.35 \mathrm{~m} / \mathrm{s})$ when defined in terms of traverse velocity of the penetrator nose. Thus, for the 16-ply specimen, the penetrator perforated the thickness at about $E_{p e r}=55 \mathrm{~J}$ (obtained by averaging two impact energies for partial penetration and two for complete penetration through the plate thickness). This corresponds to perforation limit velocity of $9.2 \mathrm{~m} / \mathrm{s}$ from Equation (6). The perforation limit velocity can be determined from Figure $12 \mathrm{~b}$ by extrapolating the line to a zero residual velocity to obtain $V_{P L} \approx 8.55 \mathrm{~m} / \mathrm{s}$ compared to $9.2 \mathrm{~m} / \mathrm{s}$ from direct measurement. The above analysis is only an approximation. In general, studies have shown that perforation limit for metals depend not only on the kinetic energy of the projectile, but on the shape of the projectile and properties of the interface in contact (Vinson \& Woldersenbet, 2001). Damage in a dynamic process driven by wave propagation is caused more by the interaction of the compressive wave than the penetrator. Delamination and development of surface crack, for example, result from the tensile release wave on the rear surface of the specimen. Thus, a perforation limit in a laminated composite will also depend on the nature of the wave phenomenon.

The results above clearly show that a threshold kinetic energy exists above which crack will be initiated in a composite plate. The crack length and damage size are expected to increase sharply with impact energy above this threshold value. One must note, however, that other lower energy damage effect such as matrix cracking and delamination are possible before the indicated crack.

\section{Conclusions}

The P-SHPB system was employed to examine the dynamic response of graphite/epoxy composite materials. In the analysis, single mode as well as mixed modes of fracture failures of laminated composites were discusses. Although a combination of these damage modes is possible internally or visibly, visible surface damage generally occurs at higher energy than internal damage. Following conclusions can be drawn in the study as:

- Strain rate, loading force, particle velocity and energy absorbed increase with the increase of striker impact energy. The residual energy is slightly higher for thicker laminate for the same impact energy, but is high sensitive to strain rate effect and more significant for thicker than the thinner specimen. The residual energy increases with particle velocity and displacement but higher for thin specimen than the thick sample due to higher elastic strain energy released in thick laminate.

- Four failure modes can be differentiated between non visible internal damage and visible rear surface damage. Mode I is characterized by elastic failure such as micro-buckling of the fibers or initiation of matrix micro cracks. Mode II is characterized by the onset of crack propagation and delamination leading to plastic deformation in Mode III as the bulk modulus of the specimen increases. The system and plate returns to equilibrium in Mode IV by losing some of the absorbed strain energy. 
- Perforation limit velocity was estimated from surface crack initiation velocity which was obtained by extrapolating the (impact velocity) ${ }^{2}$ and crack length curve to a zero-damage length and determining the velocity value. A threshold kinetic energy exists above which crack will be initiated, and the crack length and damage size are expected to increase sharply with impact energy above this threshold value.

\section{References}

Aktas, M., Balcioglu, H. E., Aktas, A., Turker E., \& Deniz, M. E. (2012). Impact and post impact behavior of $\begin{array}{llll}\text { layer fabric composites. Compos. } & \text { Struct., } & \text { 94, 2809-2828. }\end{array}$ http://dx.doi.org/10.1016/j.compstruct.2012.04.008

Bickle, L. W. (1970). An introduction of the use of strain gages for the measurement of propagating strain wave. Sandia Laboratories, Albuquerque, NM.

Chen, X., \& Chandra, N. (2004). The effect of heterogeneity on plane wave propagation through layered composites. Compos. Sci. Tech., 64, 1477-1493. http://dx.doi.org/10.1016/j.compscitech.2003.10.024

Dee, A. T., Vinson, J. R., \& Sankar, B. V. (1997). Effects of high strain rate compression on the mechanical properties of a uniweave AS4/3501-6 composite laminate with through-thickness stitching. AIAA/ASME/ASCE/AHS 38th SDM conf., Orlando, FL, Paper No. AIAA-97-1048, 945-954. http://dx.doi.org/10.2514/6.1997-1048

Espinosa, H. D., Dwivedi, S., \& Lu, H. -C. (2000). Modeling impact induced delamination of woven fiber reinforced composites with contact/cohesive laws. Comput. Methods in Appl. Mech. Eng., 183, 259-290. http://dx.doi.org/10.1016/S0045-7825(99)00222-4

Hosur, M. V., Adbullah, M., \& Jeelani, S. (2005). Studies on the low-velocity impact response on woven hybrid composites. Compos. Struct., 67, 253-315. http://dx.doi.org/10.1016/j.compstruct.2004.07.024

Kang, T. J., \& Lee, S. H. (1994). Effect of stitching on the mechanical and impact properties of woven laminate composite. J. Compos. Mater., 28, 1574-1587. http://dx.doi.org/10.1177/002199839402801604

Nwosu, S. N., \& Czarnecki, G. (1997). Dynamic crack propagation and perforation of laminated composites using a Split Hopkinson Pressure Bar. Australian Compos. Struct. Soc., 1153-1161.

Nwosu, S. N. (1997). Dynamic crack propagation by high speed imaging. Proceedings of the Fourth International Conference on Composites Engineering, Hawaii, 741-742.

Rossing, T. D., \& Russell, D. A. (1990). Laboratory observation of elastic waves in solids. Am. J. Phys., 58, 1153-1162.

Shyr, T. W., \& Pan, Y. H. (2003). Impact resistance and damage characteristics of composite laminates. Compos. Struct., 62, 193-203. http://dx.doi.org/10.1016/S0263-8223(03)00114-4

Sierakowski, R. L. (1997). Strain rate effects in composites. Appl. Mech. Rev., 50, 741-761. http://dx.doi.org/10.1115/1.3101860

Tan, K. T., Watanabe, N., \& Iwabori, Y. (2012). Impact damage resistance, response and mechanics of laminated composites reinforced by through-thickness stitching. Int. J. Damage Mech., 21(1), 51-80. http://dx.doi.org/10.1177/1056789510397070

Vaidya, U. K., Jadhav, N. C., Hosur, M. V., Gillespie Jr., J. W., \& Fink, B. K. (1999). Influence of through-the-thickness stitching on the high strain rate impact response of resin infused S2-glass/epoxy composites. Proceedings of American Society for Composites $14^{\text {th }}$ Technical Conference, Fairborn, OH, 141-151.

Vinson, J. R., \& Woldesenbet, E. (2001). Fiber orientation effects on high strain rate properties of graphite/epoxy composites. J. Compos. Mater., 35, 509-521. http://dx.doi.org/10.1177/002199801772662136

Waas, A. M., Takeda, N., Yuan, J., \& Lee, S. H. (1997). Static and dynamic compressive behavior of glass fiber reinforced unidirectional composites. In: Gibson RF and Newaz GM, editors. Proceedings $12^{\text {th }}$ Annual Technical American Society for Composites Conference, Dearborn, MI, 552-561.

Weeks, C. A., \& Sun, C. T. (1998). Modeling non-linear rate dependent behavior in fiber-reinforced composites. Compos. Sci. Tech., 58, 603-611. http://dx.doi.org/10.1016/S0266-3538(97)00183-8

Woldenbet, E., \& Vinson, J. R. (1997). Effect of specimen geometry in high strain rate testing of graphite/epoxy composites. In Proc. of $38^{\text {th }}$ AIAA/ASME/ASCE/AHS/ASC. Struc. Dyn. And Matl. Conf., 2, 927-934.

Zukas, J. A., Nicholas, T., Swift, H., Greszczuk, L. B., \& Curran, D. (1992). Impact dynamics. Kreiger 


\section{Publishing Co.}

\section{Copyrights}

Copyright for this article is retained by the author(s), with first publication rights granted to the journal.

This is an open-access article distributed under the terms and conditions of the Creative Commons Attribution license (http://creativecommons.org/licenses/by/3.0/). 